Type of the Paper: Article

\title{
Efficiency of Artificial Neural Networks in Determining Scour Depth at Composite Bridge Piers
}

Ata Amini ${ }^{1 *}$, Shahriar Hamidi ${ }^{2}$, M. A. Malek ${ }^{3}$, T. A. Mohammad ${ }^{4}$, Ataollah Shirzadi ${ }^{5}$ and Javad Behmanesh $^{6}$

${ }^{1}$ Kurdistan Agricultural and Natural Resources Research and Education Center, AREEO, Sanandaj, Iran(AA); a.amini@areeo.ac.ir;ata_amini@yahoo.com.

${ }^{2}$ Water Engineering Department, Urmia University, Urmia, Iran (SH); s.hamidi@ uok.ac.ir

${ }^{3}$ Institute of Sustainable Energy, ISE, University Tanaga Nasionalm, Selangor, 43000, Malaysia (MA); Marlinda@uniten.edu.my

${ }^{4}$ Department of Water Resources Engineering, College of Engineering, University of Baghdad (TA); thamer@gmail.com

${ }^{5}$ Department of Rangeland and Watershed Management, Faculty of Natural Resources, University of Kurdistan, Sanandaj, Iran (AS); a.shirzadi@uok.ac.ir

${ }^{6}$ Water Engineering Department, Urmia University, Urmia, Iran (JB); j.behmanesh@urmia.ac.ir

*Corresponding author,a.amini@areeo.ac.ir;ata_amini@yahoo.com

Tel: 00989183714538

https://orcid.org/0000-0001-9358-185X

Author ID: 49361121300 


\title{
Efficiency of Artificial Neural Networks in Determining Scour Depth at Composite Bridge Piers
}

\begin{abstract}
Scouring is the most common cause of bridge failure. This study was conducted to evaluate the efficiency of the Artificial Neural Networks (ANN) in determining scour depth around composite bridge piers. The experimental data, attained in different conditions and various pile cap locations, were used to obtain the ANN model and to compare the results of the model with most well-known empirical, HEC-18 and FDOT, methods. The data were divided into training and evaluation sets. The ANN models were trained using the experimental data, and their efficiency was evaluated using statistical test. The results showed that to estimate scour at the composite piers, feed-forward propagation network with three neurons in the hidden layer and hyperbolic sigmoid tangent transfer function was with the highest accuracy. The results also indicated a better estimation of the scour depth by the proposed ANN than the empirical methods.
\end{abstract}

Keywords: Local Scour; Sediment; Bridge Design; Pier Geometry; ANN. 


\section{Introduction}

Bridges play an important role in transportation. The most important factor in the collapse of the bridges is the creation and expansion of scouring [1]. Therefore, understanding the scouring mechanisms and scour depth determination around the bridges is of great importance. Determining the depth of scouring is important in this regard, which indicates the potential for destruction of the flow around the structure and in designing the dimensions of the foundation. Most studies are based on simple geometric shapes [2]. However, the composite piers consisting of three components; column, pile cap and pile groups, have been considered in the design of bridges extensively [3-6]. Therefore, it is essential to predict the depth of scouring in such piers. Most of the existing equations were obtained based on laboratory data which do not estimate the scour depth with sufficient accuracy in the field. Although research has been conducted in this regard, the available research indicates that there is a lack of valid relationships to predict scour depth [7]. This inaccuracy is due to the variety of parameters affecting the depth of scouring. Therefore, there is a lot of research to offer new ways of reforming existing relationships [4]. Most of the prediction depths for the equilibrium scour depth were based on empirical methods. In order to obtain these formulae, both laboratory and field data were used. The Colorado State University equation (CSU) or HEC-18 is one of these methods. The HEC-18 equation is being continuously revised and proposed for many years by the American Highway Administration (FHWA) to calculate the scour depth at the piers with simple and compound geometries [8]. The method provided by the Florida State Department of Transportation (FDOT) is one of the other commonly used methods for estimating scouring in composite piers. Apart from most of the existing methods which using superposition method, [3] proposed a method that, based on field data, gives better estimates of the scour depth at the composite piers than existing methods [9]. The results of [3] also showed that the maximum scour depth occurs when the pile cap is exposed to the flow and is undercutting. A safe and applicable prediction of scour depth at a complex pier was considered as $90 \%$ of the pile cap scour depth when extended within streambed [3].

In recent years, some local scour depth estimation studies have been proposed based on new methods, including Artificial Neural Networks (ANNs). An intelligent fuzzy radial basis function neural network inference model (IFRIM) was proposed to predict local scour depth at simple bridge piers [10]. The model used a hybrid model 
of the fuzzy logic, the artificial bee Colony algorithm and radial basis function neural network. [11] conducted a study on the comparison of two neural and neural networks models in estimating the scour depth at the bridges and concluded that the neural network could better estimate scour depth than neurosis. The ability of the neural network was studied, to estimate the scour depth, compared to the experimental formulas using 165 laboratory data [12]. They observed that the Generalized Regression Neural Network (GRNN) has a better estimate of the scour depth than empirical methods. The results of this study were confirmed by [13] in clear-water and live-bed conditions. In the pile group, [14, 15] emphasized the accuracy of the neural network and the neuro-fuzziness system in comparison with empirical methods. The variation of variables affecting scouring in complex geometric piers was less studied. Limited laboratory data is available. Also, the ability of the neural network to predict the scour depth in this type of bridge piers is not investigated. In this research, using existing laboratory data, ANN performance in predicting scour depth around the complex bridge piers was investigated, and the results of this method were compared with the most well-known empirical methods. Providing optimal artificial network and the effect of effective parameters on the scour depth in the composite bridges were also studied.

\section{Research method}

\subsection{Dimensional analyses}

The variables affecting the depth of scour can be divided into three groups of flow, sediment and streambed characteristics. Each of these characteristics is expressed by a number of variables. In the simple circular pile, assuming that the pile is in the flow path, the sediments are no cohesive and uniform and the flow depth is constant, the relation between the equilibrium scour depth $\left(y_{s}\right)$ and the dependent parameters can be determined as follow [14]:

$y_{s}=f\left(\rho, U, y, g, d_{50}, U_{c}, D\right)$

The dimensionless form of Eq. (1) can be expressed as Eq. (2):

$\frac{y_{s}}{D}=f\left(\frac{U}{U c}\right.$ or Fr. $\left.\frac{y}{D} \cdot \frac{d_{50}}{D}\right)$

where $\rho$ is flow density, $U$ is approach flow velocity, $y$ is flow depth, $g$ is gravity acceleration, $d_{50}$ is the average particle size, $U_{c}$ is critical velocity for sediment movement and $D$ is pile width (diameter). The number of variables affecting 
scouring in complex pier is much more complicated. In empirical methods, to determine the scour depth at composite piers, the equivalent diameter $\left(b_{e}\right)$ which is the diameter of a circular pier that produces scour depth equal to the composite piers, for the same sediment and flow conditions, is used. Dimensional analysis for $b_{e}$ in composite piers can be expressed as follows [5]:

$\frac{y_{s}}{b c}$ or $\frac{b e}{b c}=f\left(\frac{U}{U_{c}}\right.$ or $\left.F r \cdot \frac{y}{b c} \cdot \frac{b c}{b p c} \cdot \frac{b c}{d_{50}} \cdot \frac{T}{b p c} \cdot \frac{Y}{b c} \cdot \frac{f c l}{b c} \cdot \frac{f c b}{b c} \cdot k s c \cdot k s p c \cdot \frac{b p}{b c} \cdot m \cdot n \cdot \frac{s p b}{b p} \cdot \frac{s p l}{b p}\right)$

where $b_{c}$ is width of column component at complex pier, $b_{p c}$ is width of pile cap component $\mathrm{T}$ is pile cap thickness, $f c l$ is longitudinal extension length of pile cap faces out from column face $f c b$ is transversal extension length of pile cap, $\mathrm{Y}$ is pile cap location relative to undisturbed streambed, $\mathrm{K}_{\mathrm{sc}}$ and $\mathrm{K}_{\mathrm{spc}}$ are the shape factor for the column and the pile cap, $b_{p}$ is the diameter of the piles, $m$ and $n$ are the number of piles perpendicular and in line with the flow, $S_{p b}$ is pile spacing width and $S_{p l}$ is pile spacing length. The dimensionless form of Eq. (3) can be expressed as Eq. (4):

$\frac{y_{s}}{b c}$ or $\frac{b e}{b c}=f\left(\frac{U}{U_{c}}\right.$ orFr $\left.\cdot \frac{b c}{b p c} \cdot \frac{y}{b c} \cdot \frac{Y}{b c} \cdot \frac{f c l}{f c b} \cdot k s c \cdot k s p c\right)$

Figure (1) shows a view of a composite piers. The variables affecting scouring are also shown in Figure (1). 


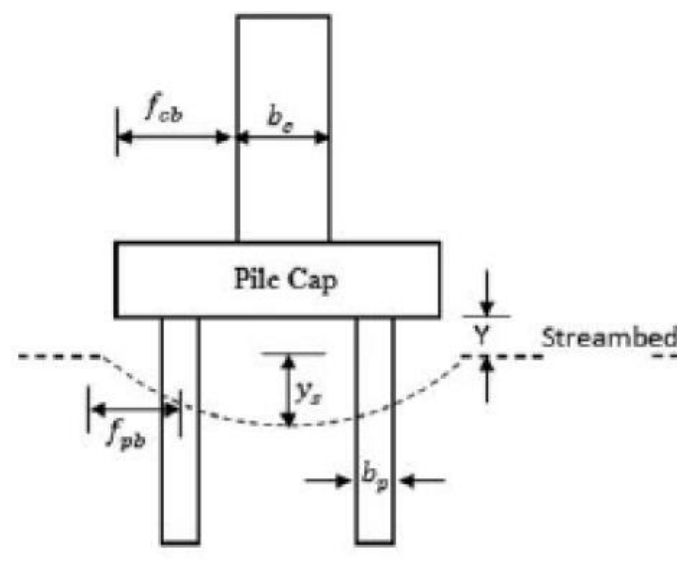

(a) Upstream view

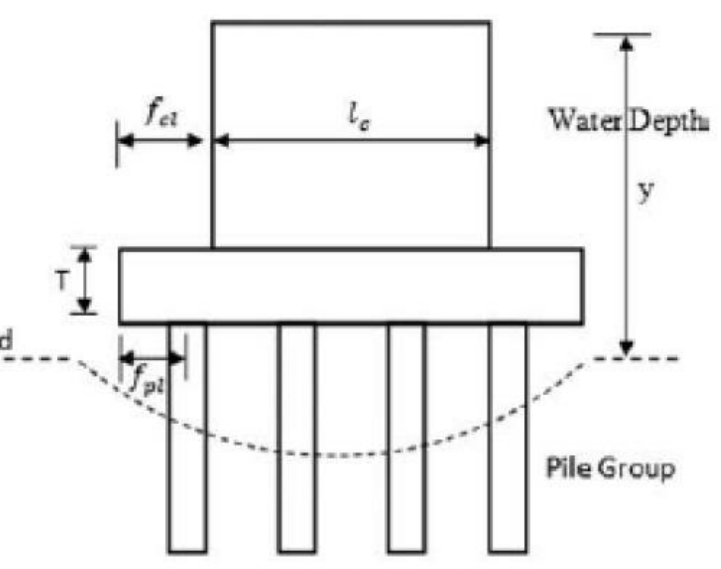

(b) Side view

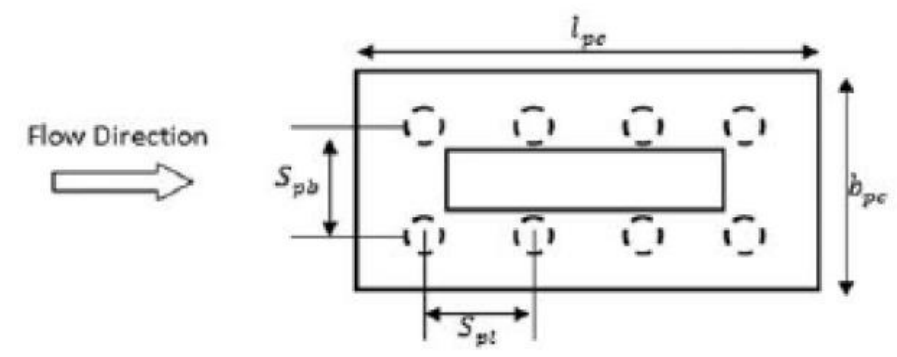

(c) Plan view

Fig. 1. Compound pier parameters (Amini and Mohamad 2017)

By analyzing these variables, empirical methods have been extracted to estimate the scour depth at the composite piers.

\subsection{Empirical Methods}

\subsubsection{FDOT Method}

The FDOT proposed a method for scouring in two different cases: when the position of the pile cap is above and within the undisturbed streambed [16]. The method used to estimate the equilibrium depth of scouring in complex piers is based on the assumption that complex foundations can be represented by an effective diameter of the circular simple pile $\left(D^{*}\right.$ or $b_{e}$ ). Total $D^{*}$ for the complex piers can be obtained by adding the effective diameter of each of the complex pier components. This method is expressed in terms of Eq. (5).

$D^{*}=D^{*}{ }_{c o l}+D^{*}{ }_{p c}+D^{*}{ }_{p g}$

where $D^{*}{ }_{c o l} . D^{*}{ }_{p c}$ and $D^{*}{ }_{p g}$ are the effective diameter of the column, pile cap and pile group respectively. The effective diameter of each component is a function of the 
pile shape, size, and location of the water and streambed, as well as flow angle of attack [8].

\subsubsection{The HEC-18 Method}

In the third version of the HEC-18, it was suggested to use the superposition method to estimate the scour depth around piers with composite geometry. The superposition method is given in Eq. (6):

$y_{s}=y_{\text {Spier }}+y_{S p c}+y_{S p g}$

where $y_{s}$ is the depth of scouring around the complex pier, $y_{\text {Spier }}$ is the scour depth due to the column, $y_{S p c}$ is the scour depth for the pile cap and $y_{S p g}$ is the scour depth for the pile group located below the pile cap.

\subsection{Research data}

To obtain the ANN model and to compare the results of the model with those of empirical methods, two sets of laboratory data obtained in different conditions, were used. The first series of experiments was performed by the first author of this manuscript in a laboratory flume with a length of $46 \mathrm{~m}$, a width of $52 \mathrm{~m}$ and a depth of $1.9 \mathrm{~m}$. In these experiments, the flow rate was kept at $138 \mathrm{l} / \mathrm{s}$ and the depth of water was maintained at $0.24 \mathrm{~m}$. This depth, in terms of the width of the equivalent width/diameter of the compound piers, provides shallow water conditions. The requirement for shallow water stated as $y / D^{*}<0.7$ by $[2,7,17,18]$. A part of the laboratory flume with a length of $15 \mathrm{~m}$ filled up as the test area with uniform cohesiveness sediment with a thickness of $0.55 \mathrm{~m}$ and an average diameter of $d_{50}=0.8 \mathrm{~mm}$ to achieve maximum scour depth and prevent forming dune and ripple. In order to uniformly assume sediments and minimizing the effect of the armor layer, sediment with a geometric standard deviation of $\sigma_{g}=1.3$ was used. This value is less than $\sigma_{g}=1.4$ which is recommended by [2] to avoid sediment non-uniformity. Since the maximum equilibrium scour depth occurs in clear-water conditions, the experiments were carried out in clear water at a velocity of $U=0.95 U c$. More details of these experiments are available at $[3,1]$.

The second series of laboratory data was extracted by [4]. The experiments were carried out in a $4 \mathrm{~m}$ long flume with a width of $0.41 \mathrm{~m}$ and a height of $0.25 \mathrm{~m}$. The flume was with a recess where the experiments were carried out. This recess is 0.8 $\mathrm{m}$ below the streambed and was with $4 \mathrm{~m}$ length. The depth of water inside the flume 
was adjusted by a sliding gate at the end of the flume. In most experiments, the conditions for the formation of shallow water in flume have been observed. All experiments were conducted in the clear-water condition. Two types of sediment with average particle size $d_{50}=0.25$ and $0.98 \mathrm{~mm}$ were used with $\sigma_{g}=1.45$ and 1.13 . The scour depth is affected by sediment coarseness which is defined as $D / d_{50}$ [1921]. To avoid sediment coarseness effect, $D / d_{50}$ should be greater than 50 . In these experiments, the $D / d_{50}$ was between 16 and 124 which is within a reasonable range. The duration of each experiment was considered greater than 7 hours. After each experiment, the dimensions of the scour hole were measured with a point gage of 1 $\mathrm{mm}$ precision [4]. Specifications of sediments used in [7, 4] are presented in Table (1). In Table (1), $S_{s}$ is the relative sediment weight, $U_{c} *$ is the critical shear velocity $(\mathrm{m} / \mathrm{s})$.

Table 1. Specifications of sediments used to extract data

\begin{tabular}{ccccccccc}
\hline Data & $\sigma_{\mathrm{g}}$ & $\begin{array}{c}\mathrm{d}_{16} \\
(\mathrm{~mm})\end{array}$ & $\begin{array}{c}\mathrm{d}_{50} \\
(\mathrm{~mm})\end{array}$ & $\begin{array}{c}\mathrm{d}_{84} \\
(\mathrm{~mm})\end{array}$ & $\begin{array}{c}\mathrm{d}_{90} \\
(\mathrm{~mm})\end{array}$ & $\begin{array}{c}\mathrm{Uc}^{*} \\
(\mathrm{~m} / \mathrm{s})\end{array}$ & $\begin{array}{c}\mathrm{Uc} \\
(\mathrm{m} / \mathrm{s})\end{array}$ & $\mathrm{Ss}$ \\
\hline Amini et al. (2014) & 1.33 & 0.62 & 0.81 & 1.1 & 1.23 & 0.02 & 0.38 & 2.65 \\
\hline Ashtiani et al. (2010) & 1.54 & 0.15 & 0.25 & 0.36 & - & 0.02 & - & 2.65 \\
& 1.13 & 0.85 & 0.98 & 1.1 & - & 0.02 & - & 2.65 \\
\hline
\end{tabular}

\subsection{Artificial Neural Network model}

One of the new methods for estimating the variables associated with numerous variables is the ANN model. This model uses information processing on experimental data and results from the human brain [22, 23]. The structure of the ANN is determined by the try and error process. The size of the input and the number of hidden layers of the network varies and depends on the prediction precision. Each network requires three sets of data including training, validation and testing to be generated. The ANN needs a training process to adjacent the output as closely as possible to the target vector. In this research, the Levenberg-Marquardt algorithm was used to identify the best method with the highest accuracy for network training. This algorithm is a method for finding the minimum of a non-linear multivariable function, which is a standard method for solving the least squares problem for nonlinear functions [22]. After training, the ANN model was verified. Observation 
values were compared with the corresponding estimated values and the accuracy of the model was measured. The test process should be performed for the final control of the model [22]. To evaluate the efficiency of each model and its ability to accurately estimate the efficiency of the relationships studied in this study, three objective functions including Mean Absolute Error (MAE), Root Mean Square Error (RMSE) and Correlation Coefficient (R) were used. These functions are expressed in terms of Eq. (7) to (9) respectively:

$$
\begin{aligned}
& M A E=\frac{1}{N} \sum_{i=1}^{N}\left|O_{i}^{p}-O_{i}^{o}\right| \\
& R M S E=\sqrt{\frac{\sum_{i=1}^{N}\left(o_{i}^{p}-O_{i}^{o}\right)^{2}}{N}} \\
& R=\left[\frac{\sum_{i=1}^{N}\left(O_{i}^{o}-\bar{o}^{o}\right)\left(O_{i}^{o}-\bar{o}^{p}\right)}{\sqrt{\sum_{i=1}^{N}\left(O_{i}^{o}-\bar{O}^{o}\right)^{2}} \sqrt{\sum_{i=1}^{N}\left(O_{i}^{o}-\bar{O}^{p}\right)^{2}}}\right]
\end{aligned}
$$

where $O_{i}^{o}$ is the recorded values (observed), $O_{i}^{p}$ is calculated values (network), $N$ is number of data, $\bar{O}^{o}$ is mean values of the observed data and $\bar{O}^{p}$ is the mean values of estimated data. In this research, according to the dimensional analysis presented and the results of laboratory investigations, the order of the input parameters are as the flow depth $(y)$, pile cap thickness $(T)$, the median particle size $\left(d_{50}\right)$, width of pile cap component $\left(b_{p c}\right)$, the width of the column $\left(b_{c}\right)$, longitudinal extension length of pile cap extended from column face $(f c l)$, transversal extension length of pile cap $(f c b)$, model location $(Y)$, flow velocity $(U)$ and critical velocity $\left(U_{c}\right)$. The complex pier scour depth was considered as the output of the model. In constructing the ANN model, the number of input and output layer neurons should be equal to the number of input and output parameters. While the number of hidden layers and the numbers of their neurons are determined empirically. In this research, the number of suitable neurons and hidden layers were obtained using network performance through training process compare with experimental data. In estimating the scour depth in compound piers, the ANN with a hidden layer was selected. Considering different neurons with try and error, the number of optimal neurons was selected to produce the least error rate and the highest correlation coefficient. In this research, by comparing the results of the model with the recorded data, the ANN model of the back propagation error with 3 neurons in the hidden layer was selected as the optimal network. Given that closely related neurons behave similarly and their error is close, the total number of selected neurons was chosen as $1,2,3,4,5,6,7,8,9$ and 10 . In 
order to avoid model divergence, the number of hypotheses was limited to 10. An overview of the ANN model with the post-propagation error of 3 neurons is shown in Figure 2.

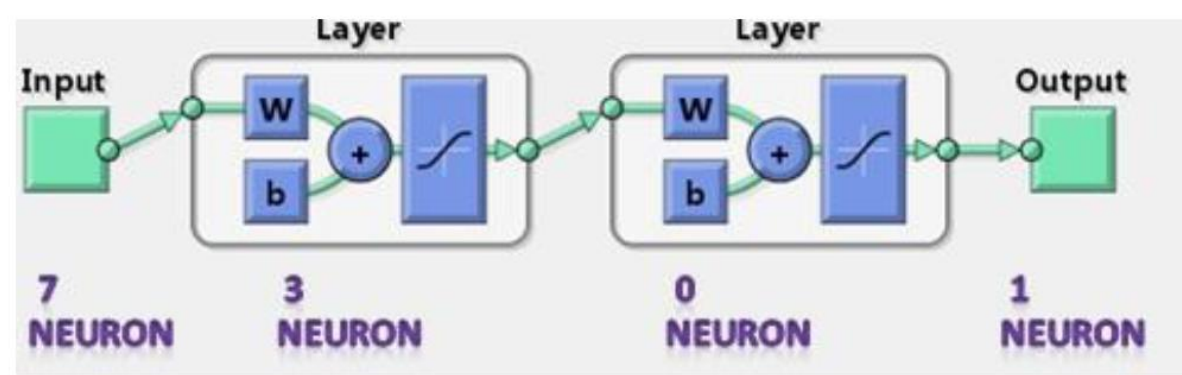

Fig. 2. Neuronal neural network poster error with 3 neurons

3.

\section{Results and Discussion}

\subsection{ANN model}

Training, validation, and evaluation of ANN model were performed using available experimental data. The best model was selected based on the error rate of the model and the correlation coefficient between the observed and estimated data. By performing various stages, the pre-release network of post-propagation error with three neurons in the hidden layer was selected as the optimal ANN model. The efficiency of the ANN model is presented in Figure 3 on the training data from the beginning of training until weighing and bias adjustment.

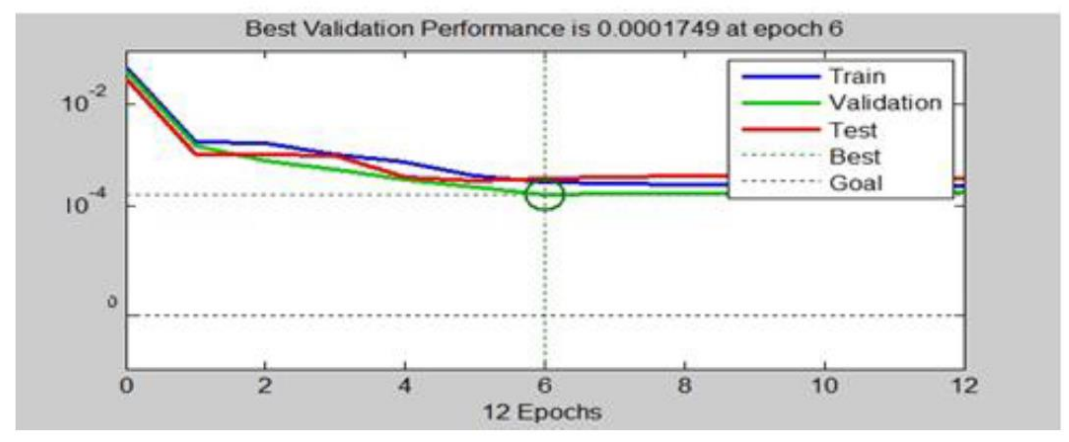

Fig. 3. Neural network efficiency with 3 neurons in hidden layer 
As shown in Figure 3, the error rate during the training is based on the average squared error with generalization, and the generalization technique was used to avoid model divergence. Comparison of estimated scour depth with that of observation for training data, validation, total data and evaluation are shown in Figure 4.

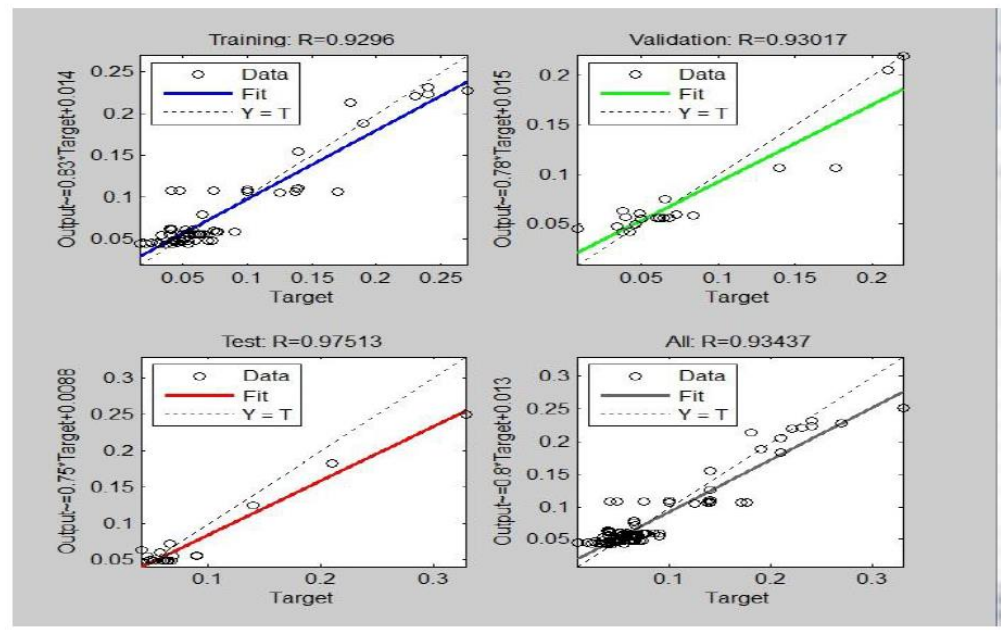

Fig. 4. Estimated and expected scour depths on training, validation, evaluation and entire data

The proper fitting of the data in these charts and the high correlation coefficient indicates the good fit of the model and its ability to predict scour depth using input variables.

\section{2. Comparison of Empirical and ANN models}

In this research, to evaluate the capability of HEC-18, FDOT and the obtained ANN model to estimate the scour depth in compound piers, estimated scour depth against observed values were compared. Observation and estimated data in various methods are presented in Table (2).

Table 2. Estimation of final scouring data of composite bridges in different methods

\begin{tabular}{ccccc}
\hline Row & $\begin{array}{c}\text { Observed } \\
(\mathrm{cm})\end{array}$ & $\begin{array}{c}\text { ANN Model } \\
(\mathrm{cm})\end{array}$ & \multicolumn{2}{c}{ Experimental Formula Estimate } \\
\cline { 4 - 5 } & 0.066 & 0.069 & 0.070 & FDOT $(\mathrm{cm})$ \\
\hline 1 & 0.055 & 0.066 & 0.120 & 0.100 \\
3 & 0.066 & 0.065 & 0.110 & 0.100 \\
4 & 0.078 & 0.063 & 0.110 & 0.050 \\
5 & 0.055 & 0.060 & 0.060 & 0.100 \\
6 & 0.061 & 0.059 & 0.050 & 0.050 \\
\end{tabular}




\begin{tabular}{ccccc}
7 & 0.066 & 0.058 & 0.050 & 0.020 \\
8 & 0.055 & 0.056 & 0.040 & 0.020 \\
9 & 0.052 & 0.055 & 0.040 & 0.020 \\
10 & 0.130 & 0.121 & 0.080 & 0.160 \\
11 & 0.130 & 0.119 & 0.080 & 0.150 \\
12 & 0.110 & 0.176 & 0.080 & 0.120 \\
13 & 0.102 & 0.116 & 0.070 & 0.120 \\
14 & 0.078 & 0.115 & 0.140 & 0.100 \\
15 & 0.081 & 0.114 & 0.160 & 0.190 \\
16 & 0.100 & 0.114 & 0.160 & 0.190 \\
17 & 0.124 & 0.113 & 0.170 & 0.190 \\
18 & 0.113 & 0.112 & 0.110 & 0.170 \\
19 & 0.103 & 0.113 & 0.120 & 0.170 \\
20 & 0.134 & 0.111 & 0.120 & 0.150 \\
21 & 0.137 & 0.110 & 0.130 & 0.150 \\
22 & 0.116 & 0.109 & 0.130 & 0.150 \\
23 & 0.110 & 0.108 & 0.130 & 0.140 \\
\hline
\end{tabular}

In order to compare the performance of these methods, the results are depicted in Figure 5. In Figure 5, lines of the best and lowest errors are highlighted by $20 \%$.

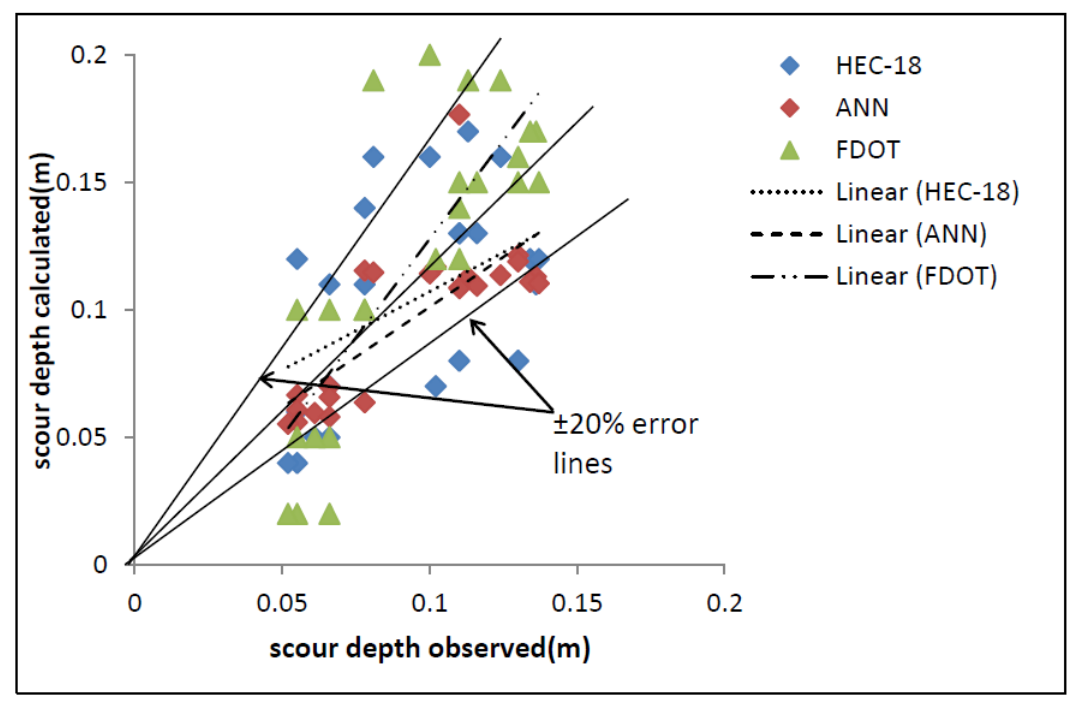

Fig. 5. Performance of scour depth estimation methods in composite piers

Figure 5 shows the existence of a large number of estimates with errors of more than $\pm 20 \%$ by empirical methods. This number is more visible in the FDOT method. In addition, with increasing scour depth, the accuracy of these methods was decreased. The results of this study are consistent with the findings of [7, 3]. Meanwhile, [4] expressed similar results and proposed modifying factors to adjust these methods. 
To compare the efficiency of the proposed ANN model in this study and the experimental methods, the statistics test are presented in Table (3).

Table 3. Models evaluation results

\begin{tabular}{cccc}
\hline Criteria & FDOT & HEC-18 & ANN \\
\hline MAE & 0.0368 & 0.032 & 0.011 \\
RMSE & 0.0452 & 0.038 & 0.015 \\
$\mathrm{R}^{2}$ & 0.639 & 0.607 & 0.950 \\
\hline
\end{tabular}

The results presented in Table (3) indicated that the post-propagation ANN model with a number of 3 neurons in the hidden layer, due to having the lowest error value and the highest correlation coefficient, provides an appropriate estimation of the equilibrium scour depth in the composite pier relative to the other methods.

\subsection{Sensitivity Analysis}

Sensitivity analysis was performed to determine the effect of each parameter on the estimation of the equilibrium scour depth in the composite bridge piers. To do this, the optimal ANN model was re-trained with the absence of any of the input parameters of the model. Then the error rate and the correlation coefficient of the new model were calculated. Table (4) shows the results of the sensitivity analysis for various parameters. To better understanding the importance of each of the parameters, the results are sorted in descending order.

Table 4. Sensitivity analysis

\begin{tabular}{lcccc}
\hline Ignored parameter & Abbreviation & MAE & RMSE & R \\
\hline Height of model & $Y$ & 0.0432 & 0.0555 & 0.912 \\
Width of pile cap & $b \mathrm{pc}$ & 0.0389 & 0.0484 & 0.949 \\
Width of column & $b \mathrm{c}$ & 0.0343 & 0.0465 & 0.874 \\
Longitudinal extension length of pile & $f \mathrm{cl}$ & 0.0330 & 0.0393 & 0.815 \\
cap & & & & \\
Transversal extension length of pile cap & $f \mathrm{cb}$ & 0.0314 & 0.0385 & 0.946 \\
Pile cap thickness & $T$ & 0.0310 & 0.0320 & 0.951 \\
Mean velocity of approach flow & $U$ & 0.0228 & 0.0280 & 0.926 \\
Critical velocity for sediment & $U \mathrm{c}$ & 0.0202 & 0.0252 & 0.770 \\
Median sediment size & $d 50$ & 0.0122 & 0.0157 & 0.911 \\
Depth of approach flow & $y$ & 0.0111 & 0.0142 & 0.948 \\
\hline
\end{tabular}


It can be concluded from Table (4) that the most important parameter is the pile cap location from the undisturbed stream bed and the lowest effect parameter is flow depth (h). In Table 4, the order of the effective parameters on the amount of scour depth is shown. It should be noted that in the use of the results from Table (4) the conditions and limitations of the laboratory data used in this research should be taken into account.

\section{Conclusions}

In this research, using the experimental data, the ANN model was obtained to predict the scour depth at the composite piers of the bridges, and its efficiency was evaluated in comparison with empirical methods. The most obvious results of this research can be summarized as follows:

1. The ANN model by selecting feed-forward propagation with three neurons in the hidden layer and a sigmoid tangent transfer function provides reasonable results in predicting the scour depth.

2. The proposed ANN model provides better results than the empirical methods indicated that ANN could be used to predict the scour depth of composite piers as an accurate tool.

3. Analysis of scour depth sensitivity to effective variables, based on laboratory data used in this research, showed that the pile cap location and the flow depth were with the most and the least effects on the scour depth.

Estimating the scour depth in composite piers, understanding the complexity of the phenomena, the scouring mechanism, and also providing an appropriate method for calculating the scour depth in these piers, requires more researches and field data. In this regard, further research is required on composite piers composed of different geometry components under different conditions of flow and sediment. It is also necessary to use field data for verifying the method presented in this study.

\section{Author Contributions}

A.A. conducted the experimental modeling, collected the data and revised original draft preparation; S.H. conceived and designed the framework of ANN modeling and performed the model simulation; A.S. writing - review and editing the paper, 
T.A. and M.A. provided critical comments in planning this paper and edited the manuscript.

\section{Conflicts of Interest}

The authors declare no conflict of interest. 


\section{References}

1. Amini A. and Solaimani, N. The Effects Of Uniform and Nonuniform Pile Spacing Variations on Local Scour at Pile Groups. Georesources and Geotechnology. 2017, DOI: 10.1080/1064119X.2017.1392658

2. Melville, B.W.; Coleman, S. Bridge Scour. Auckland. NZ, 2000, 572 pages.

3. Amini, A.; and Mohamad, T.A. Local Scour Prediction around Piers with Complex Geometry. Marine Georesources and Geotechnology. 2017, 35, 6, 857-864.

4. Ashtiani, B.A.; Baratian-ghorghi, Z.; and Beheshti, A.A. Experimental Investigation of ClearWater Local Scour of Compound Piers. J. Hyd. Eng. 2010, ASCE 136 6:343-351.

5. Coleman, S.E.; Clearwater local scour at complex piers. Journal of Hydraulic Engineering 2005, 4, 131,330-334.

6. Amini A.; Mohd T.A.; Ghazali H.; Huat B.; Aziz A. A local scour prediction method for pile cap in complex piers. ICE-water management. 2010, 164, 2,73-80.

7. Amini, A.; Melville B.; Mohd T.A. Local Scour at Piled Bridge Piers Including an Examination of the Superposition Method. Canadian Journal of Civil Engineering. 2014, 41, 5, 461-471, DOI:10.1139/cjce-2011-0389.

8. Arneson, L.A.; Zevenbergen, L.W.; Lagasse, P.F.; Clopper P.E. Evaluating Scour at Bridges. Fifth edition. U.S. Depart. of Transportation. 2012, Federal Highway Administration. US.

9. Jannaty, M.H.; Eghbalzadeh A.; Hosseini S.A.; Using Field Data to Evaluate the Complex Bridge Piers Scour Methods. Canadian Journal of Civil Engineering. 2016, 43, 3, 218-225.

10. Cheng, M.-Y.; Cao, M.-T; Hybrid intelligent inference model for enhancing prediction accuracy of scour depth around bridge piers. Structure and Infrastructure Engineering. 2014, 11, 9, 1178-1189. Doi:10.1080/15732479.2014.939089.

11. Bateni, S.; Borghei, S.; Jeng, D. Neural Network and Neuro-Fuzzy Assessments for Scour Depth around Bridge Piers. Engineering Applications of Artificial Intelligence. 2007, 3, 20, 401-414.

12. Firat, M.; Gungor, M.; Generalized Regression Neural Networks and Feed Forward Neural Networks for Prediction of Scour Depth around Bridge Piers. J Advances in Engineering Software, 2009, 40, 731-737.

13. Toth, E.; Brandimarte, L. Prediction of Local Scour Depth at Bridge Piers under Clear-Water and Live-Bed Conditions: Comparison of Literature Formulae and Artificial Neural Networks. Journal of Hydroinformatics, 2011, 13, 812-824. 
14. Zounemat-Kermani, M.; Beheshti, A.; Ataie-Ashtiani, B. Estimation of Current-Induced Scour Depth around Pile Groups Using Neural Network and Adaptive Neuro-Fuzzy Inference System. Applied Soft Computing, 2009, 2, 9, 746-755.

15. Hosseini, R.; Fazloula, R.; Saneie, M.; Amini, A. Bagged Neural Network for Estimating Scour Depth around Pile Groups. International Journal of River Basin Management. 2017. 16, 401412. DOI:10.1080/15715124.2017.1372449.

16. Sheppard, D.M.; Renna, R. Bridge Scour Manual. Florida department of transportation. 605 Suwannee Street, Tallahassee, Florida, US. 2005, 129 pp.

17. Sheppard, D.; Odeh, M.; Glasser T. Large scale clear-water local scour experiments. J. Hyd. Eng. 2004, 10, 130, 957-963.

18. Melville, B.W.; Sutherland, A.J. Design Methods for Local Scour at Bridge Piers. J. Hyd. Eng. 1988, 10, 114, 1210-1226.

19. Breusers, H.N.; Raudkivi, A.J. Scouring: In Hydraulic Structures Design Manual Series. IAHR Design Manual. 1991, Balkema, Rotterdam.

20. Melville, B.W.; Chiew, Y.M. Time Scale for Local Scour at Bridge Piers. J. Hyd. Eng. 1999, $125,1,59-65$.

21. Solaimani, N.; Amini, A.; Banejad, H.; Ghazvinei, P.T. The Effect of Pile Spacing and Arrangement on Bed Formation and Scour Hole Dimensions in Pile Groups, International Journal of River Basin Management.2017, 15, 2, 219-225.

22. Hagan, M.T.; Demuth, H.B.; Beale, M. Neural Network Design, 2nd Edition. PWS Pub. Co. 1996, 1015pp.

23. Ning, J.; Li, G.; Li, S. Numerical Simulation of the Influence of Spur Dikes Spacing on Local Scour and Flow, Appl. Sci. 2019, 9, 11; https://doi.org/10.3390/app9112306 